\title{
Mediatizing the Holy Community-Ultra-Orthodoxy Negotiation and Presentation on Public Social-Media
}

\author{
Nakhi Mishol-Shauli * and Oren Golan \\ Department of Leadership and Policy in Education, University of Haifa, Haifa 34998838, Israel \\ * Correspondence: nakhish@gmail.com
}

Received: 30 May 2019; Accepted: 9 July 2019; Published: 17 July 2019

check for updates

\begin{abstract}
In recent years, media theorists stress macroscopic relations between digital communications and religion, through the framing of mediatization theory. In these discussions, media is conceptualized as a social institution, which influences religious establishments and discourse. Mediatization scholars have emphasized the transmission of meanings and outreach to individuals, and the religious-social shaping of technology. Less attention has been devoted to the mediatization of the religious community and identity. Accordingly, we asked how members of bounded religious communities negotiate and perform their identity via public social media. This study focuses on public performances of the ultra-Orthodox community in Israel, rhetorically and symbolically expressed in groups operating over WhatsApp, a mobile instant messaging and social media platform. While a systematic study of instant messaging has yet to be conducted on insular-religious communities, this study draws upon an extensive exploration of over 2000 posts and 20 interviews conducted between 2016-2019. The findings uncover how, through mediatization, members work towards reconstructing the holy community online, yet renegotiate enclave boundaries. The findings illuminate a democratizing impact of mediatization as growing masses of ultra-Orthodox participants are given a voice, restructure power relations and modify fundamentalist proclivities towards this-worldly activity, to influence society beyond the enclave's online and offline boundaries.
\end{abstract}

Keywords: WhatsApp; ultra-Orthodox; social media; messaging; fundamentalism; digital religion; mediatization; social networks; smartphones

\section{Introduction}

In the past two decades, there has been a notable proliferation in religious communities' use of online social media. While social media is often lauded as enabling open communication, identity play and leisure laden practices (Danet 2001; Shirky 2008), for religious and fundamentalist communities, its affordances raise concerns as these communities strive to uphold a broadly shared and consistent identity. Community leaders seek to hold tight control over information and its dissipation (Cohen 2017; Turner 2007; Umble 1992, p. 177), as they aim for solid and constant socialization structures to infuse piety.

Although online social networks are considered harbingers of modernity, and may be seen as individualizing both religion and communal practices (Hoover and Echchaibi 2014; Rainie and Wellman 2012), devout groups, including fundamentalists, increasingly engage social networks for religious and communal purposes (Campbell 2010; Hoffman and Schweitzer 2015). The use of platforms offering individual agency by members of groups that promote collective causes makes social network sites a new arena for ongoing identity discourse among members of bounded religious communities. Given their engagement in these newfound platforms, the question begs, of how they manifest their sense of belonging online. More specifically, we inquire how do members 
of bounded religious communities negotiate and perform their communal identity via public social network sites?

To examine this arena, this study focused on the case of Jewish ultra-Orthodoxy (Haredi), which is an insular population that has recently embraced, albeit apprehensively, new media platforms. Despite their leaders' ongoing directives and sanctions, Haredi members have significantly increased their web participation, often in a covert manner. This includes activities on social network sites (SNS), most notably that of mobile WhatsApp groups. It is contended that uncovering their SNS activities can shed light on the understanding of insular communities' lived religion' in the age of new media. This is to say, an understanding of mediatization as practiced and experienced in everyday life, and how these media platforms foster negotiation of meaning, identities and social relationships (see Lynch 2012).

To explore their online communal negotiations via WhatsApp, this study begins by briefly surveying past scholarship on mediatization and the religious community, and contextualizing the study by discussing the Haredi identity and its dispositions toward new media and social network participation. Subsequently, the study's findings are presented which include the ways that the Haredi holy community is reconstructed online through symbolic means and social action that fortify their sense of belonging. Further findings underscore a renegotiation of the Haredi enclave through a playful mode of language use, a denominational relaxation of the communities' boundaries and an opening of the group to political influence from other religious Jewish groups. Ultimately, this reflects a somewhat unexpected process of democratization as a rapidly growing body of Haredi members gain a voice and increased participation in the public sphere. With this change, new forms of power relations are formed, and we contend that the fundamentalist character of the Haredi public is incrementally transformed.

\section{Mediatization and Religious Community}

Exploring the impact of contemporary media platforms on religious communities, this study focuses on the central framing of mediatization theory. Broadly speaking, mediatization highlights changes in the relations between media institutions and other societal institutions, such as politics or religion, and how the performance of social activities through various media has increasingly become a part of the very fabric of society (Lövheim 2017). Initial studies of mediatization in religious contexts primarily focused on praxis-lenient religions in western-liberal societies. These studies found that mediatization processes loosen the bond between the believer and the local religious community. These processes were seen to foster religious individualism. In some cases, this individualism entails secularization (Hjarvard 2012), and in others, promotes types of religious beliefs deemed simple religion, referring to an abstraction in content and ideological conformity together with a relative banality of the message (Francesc-Xavier 2015). In contrast, individualization was not clearly identified in studies focusing on mediatization of close-knit religious groups that emphasize stringency. For these communities, online and offline religious expressions are closely interrelated. Accordingly, online everyday practices were found to be situated in offline mores, with mediatization enabling an emergence of secondary authority structures (Campbell and Lövheim 2011; Golan and Campbell 2015).

Current studies of mediatization and religion focus on how religious institutions adopt media logic (Golan and Martini 2019; Hutchings 2011; Rinallo et al. 2016). These studies underline the impact of online information flows on religious practices and the delivery of transcendental beliefs, yet have less scrutinized the nature of intra-communal social interaction.

In contrast to the individualizing nature of computer-mediated-communications (Rainie and Wellman 2012), some mediatization scholars underscore the communal nature of the internet. In this context, religious sites can be viewed as platforms for public social media (Hoover and Echchaibi 2014), and SNS offers new avenues for social exchange on religious and communal matters, offering a shared space for broad discussions (Shirky 2008). These publics can also be compared to danah boyd's notion of networked publics, which underscores the negotiative process by which designated groups (or publics) act in a given technological environment, as the latter shapes participants' engagement rather than dictating its behavior (boyd 2010). These publics mark an effort 
to create platforms for discourse that go beyond that of a family or regional subgroup. Accordingly, this study proposed underscoring religious networked publics to add the religious dimension to the meaning-making process that accompanies the believers' engagement with communicative platforms as a collective. A collective that can traverse regional, social or nation-based boundaries to form solidarity on elected foundations.

Paradoxically, these public platforms often bring about splitting of users into separate, almost exclusive, publics (Boczkowski et al. 2018; Vaidhyanathan 2018), fostering echo chambers (Pariser 2011) that can be divided by regional or denominational cleavages. This aspect has been understudied among religious groups, and it relates to the ways that SNS promotes or hinders social solidarity, particularly within insular groups.

\section{Ultra-Orthodox Jewish Identity and New Media}

As mentioned earlier, bounded religious communities show close interrelation between the offline and online interactions. Accordingly, a brief account on the Israeli Haredi case, and its complex and fraught affiliation with modernity and contemporary media, is noted as follows.

It bears noting that ultra-Orthodox Jewry does not constitute a single cohesive unit, but is an umbrella term for Jewish communities that aspire to traditional lifestyles while drawing on Rabbinic tradition (Brown 2017). In Israel, ultra-Orthodoxy's main strands are devout Sephardi (Shas), Lithuanians (mitnagdim), and Hassidim. These strands are divided into smaller ultra-Orthodox denominations. While having separate institutions, demographic and social developments brought these three strands to gradually adopt some of each other's shared characteristics and practices, allowing scholars to portray a general Haredi communalism.

The Haredi society in Israel is often described as a society of scholars, or an "enclave culture" (Brown 2017; Friedman 1991; Sivan 1995), in which male roles are elevated and made central, particularly regarding the role of studying the Torah day and night. To advance the enclave identity, Haredi community structures are designed to foster pious existence within rigid boundaries. Scholars define ultra-Orthodoxy to be Orthopraxic to reflect the efforts to control members' conduct. This is to say, community structures highlight praxis, the right ways to act, rather than doxy, the right beliefs (Heilman 1992; Neusner 1986).

Rather than viewing the Haredi as highly religious or conservative, which can imply a static mode, scholars have employed fundamentalism to depict this enclaved society. Sociologists studying fundamentalism contend that such Haredi groups are led by educated, text-based intellectual men who are accepted in their communities as virtuosos of the canon (Stadler 2009, p. 2). This study rejects implications that may connect the term with militant violence, yet wishes to build on the reasoning that accompanied the grand fundamentalism project of the early 1990s (Marty and Appleby). According to this reasoning, the Haredi community is seen as strongly opposed to modernity. It identifies its proponents as the enemy and, on occasion, some of its factions take action to protect its boundaries and remake society in a way that fits their creed, thus conforming with the fundamentalist framework (Heilman and Friedman 1991, p. 215; See also Gregg 2016).

Numerous precepts aim to regulate all of the believer's life spheres, including that of social conduct. Pious Haredi social conduct can be depicted through conforming to several key tenets: (1) Locality-the adhering believer must live in close physical proximity to community institutions (Heilman 1992; Tavory 2016); (2) gender segregation-gender separation is demanded on most occasions, and strongly encouraged in others (Aharoni 2014; Fader 2017; Stadler 2009); (3) external boundaries-Haredis are urged to minimize interactions with non-Haredis so as not to risk a contamination of their righteousness (Brown 2017; Friedman 1991). It should be noted that three Haredi denominations vary in how they negotiate their external boundaries. Many devout Sephardi-Haredi Jews freely consort with non-Haredi groups, particularly within their own family circles (Le' on 2009). Some leaders of the Breslov Hassidic sub-group encourage members that have become newly Orthodox (as adults) to incorporate Haredism, yet preserve aspects of their previously secular lifestyles that do not conflict with their newfound faith 
(i.e., occupation, accessibility towards technology) (see Bilu and Mark 2017). An exceptional case is that of the Haredi subgroup, Chabad. While demanding rigid external boundaries, and furnishing websites devoted for religious learning and communal networking for its members, this subgroup has been concurrently reaching out to non-Haredi Jews via the web from as early as the 1980s. This was performed though the usage of platforms such as Keshernet, an electronic bulletin board (BBS). In these online tracts, Chabad devotees launched their religious online activism (Zaleski 2002). By the end of 1993, with the blessing of the highly revered leader of Chabad, Rabbi Schneerson, the organization Chabad.org was established as the primary institution that manages and coordinates the group's web outreach (Golan 2013; Bilu and Mark 2017). Current research shows that Haredi separatism, while still strong, has become less hermetic in recent years, and Haredis increasingly participate actively in Israel's civic life and workforce (Stadler 2012; Zicherman 2014; Zoldan 2019).

Haredi members' approach to media is historically charged with apprehension and prohibitions. While religious leaders' ban of television gained large-scale compliance, restrictions on smartphone and internet use proved less effective (Cohen 2017, p. 120; Katz 2012), with a penetration rate of 43\% (Malach and Cahaner 2018).

In this regard, some of the expressed dispositions of Haredi leadership reflect ideal aspirations, while others represent practical strategies enabling Haredis to use the web and remain part of the community. The most deeply rooted ideal aspiration is that fulltime Torah scholars and children should have no web connectivity under any circumstances (Friedman 1991; Zicherman 2014). For other Haredis, spiritual leaders are leaning towards acquiescence to the web. This acquiescence utilizes computers and smartphones that allow limited web use (Kosher smartphones), aligning the previous decade's struggle for instilling solely Kosher phones with no internet access (Campbell 2010; Rashi 2013) to grassroots reality. In order to have as few Haredis as possible connect to the web, Haredi leaders frequently post warnings and organize rallies against Haredi use of the web for non-vocational purposes. However, they do not employ their full authority to prevent it entirely, and occasionally even try to set clear rules for customizing it (Abramac 2015; Finkelman 2014, p. 271). As these smartphones are not officially allowed for all, there are many variants (Katz 2012; Rosenthal and Ribak 2015). This ambivalence is evident among popular Haredi stances. Haredi interviewees tend to state that the web is dangerous, but also to highlight its merit, and, in their opinion, irrevocability (Abramac 2015; Golan and Mishol-Shauli 2018; Toor 2015).

Most studies of Haredi use of SNS examine online forums, as these were the initial social media venues to gain popularity among community members in Israel (Lev-On and Shahar 2011). These studies highlight discrepancies between communal and personal perceptions. Some forum participants described their activity as congruent with community values, even when it was not (Livio and Tenenboim-Weinblatt 2007). Other participants supported the call to avoid web connections at home on the one hand and directly acknowledged the mainstream Haredi stance that sees the web as dangerous to the Haredi community. On the other hand, the same forum users shared that their web connection, used for leisure at home, is a vital and empowering factor in their lives, not harming their piety (Lev-On and Shahar 2011).

Golan and Campbell (2015) discuss the strategies applied by the managers of a group of Haredi forums. In a forum allowing anonymity and open access, strict content supervision was applied. However, for practicing rigid initial user access, only light content and discourse control supervision were set. A close-knit and trusting online community was found allowing for more freedom of expression, suggesting that Haredi forum users feel more secure among like-minded group members. This finding is not self-evident, as anonymity is usually claimed as giving users the security to express freely (Ekstrand 2003).

Considering Haredi WhatsApp use, Abramac (2015) reports her findings after being added to a mostly American Hasidic WhatsApp group conducted in Yiddish. She describes how the online community views itself as a continuation of the offline community, particularly with regard to its basic norms and conduct. The administrator even refers to her being allowed into the group in terms 
of visitation or tourism (Abramac 2015, p. 165). Abramac also describes how various features of the application influenced group conduct, sometimes having Haredi-specific effects and sometimes general ones.

To conclude, given moral apprehensions and leaders' cautions, scholars have demonstrated the community's broad, albeit careful, use of the web for livelihood, as well as for more expressive utilities. While past research has underscored the struggles for usage, as well as internet engagement, less is known on smartphone activities, even though the communal interactions they afford are increasingly prevalent in everyday life, and impact key aspects of personal and religious life.

\section{Researching WhatsApp Groups}

\subsection{The Platform}

Since its emergence over 20 years ago, texting (SMS or short message services) have revolutionized modes of communication, allowing mobile users to send real-time text messages to individuals or groups and enabling new subcultural modes of discourse. These modes of discourse, on which scholars have conducted their studies with regard to age groups (with an emphasis on youth), gender and socio-economic differences (Zelenkauskaite and Gonzales 2017), have nonetheless largely overlooked religion and communal affiliation as a meaningful cultural variable.

An evolutionary new wave of these communicative means, mobile instant messaging (MIM) applications, have gained considerable momentum, led by its currently most popular mobile application, WhatsApp (Church and De Oliveira 2013). WhatsApp is a cross-platform instant messaging application for smartphones that enables users to send and receive location information, images, video, audio and text messages in real-time to individuals and groups of friends at no cost. Focusing on the distinct group option, WhatsApp groups include at least one administrator. The first administrator is the group's initiator. As such, administrators determine the groups' original title and primary topic. Furthermore, administrators can add and remove users, control user affordances concerning group features (e.g., picture, description, adding new members and uploading posts) and more. In contrast to older texting (SMS), MIM applications are used as SNS by many of its users, thus expanding the scope of the applications' affordances to incorporate large long lasting groups, rather than highlighting solely interpersonal communication or ad-hoc broadcasts.

Since WhatsApp boasts over a billion users in 180 countries on its website (https://www.whatsapp. com/about/ retrieved 23 April 2019), it is somewhat surprising that there is a dearth of methodological tools to rely upon when applying content analysis to groups. This is perhaps due to its relatively new application (released in 2009), and ongoing studies on other formats of texting, messaging and such, which highlight interpersonal communication. However, beyond its interpersonal proclivities, WhatsApp groups' ongoing discourse is the most pertinent to the study at hand. These groups can be viewed as speech communities, and invite an ethnographic application (also known as ethnography of communication) of discourse analysis, focusing on speech events and communities in their cultural context (Hymes 1989; Katriel 2004).

\subsection{Access and Groups Selection}

Studies on Haredi society describe hardships and challenges in their research, including a prevailing suspicion of academia as representing modern culture, and of secular researchers (Golan and Campbell 2015; Stadler 2009). Haredi society is a closed community to which we do not belong. In addition, while gradually coming to terms with the web and SNS, Haredi members are mostly unenthusiastic about discussing its impact on their lives as its use is occasionally identified with moral transgressions and profligacy. To address this research impediment, through snowballing techniques, a cadre of key informants was formed to advise on access, WhatsApp group selection and inform with regard to the interpretation of online postings. 
The findings were chiefly gleaned from an ethnographic study which consisted of analyzing (over 2000) posts and supported by semi-structured interviews (20) with Haredi WhatsApp groups' users and administrators conducted between 2016-2019.

While this study does not focus on the grounded apprehensions and/or modes of domestication of new media technologies (see Mishol-Shauli et al. 2019), its use is often debated within this population, all of which may influence and explain the Haredi proclivities that are identified in this manuscript.

Interviewees shared their apprehensions with their own mobile phone use as well as external pressures they encountered. For example, a teacher told us "the Rabbi approved, but at work I do not mention that I am using (the phone). It isn't forbidden but it is (considered) unwanted and unworthy". Another interviewee expressed his disdain for smartphones' leisure use saying "when you burn time over the internet, it's a disaster, tantamount to secularization ..." ". These interviewees, among others, expressed an ambivalence that is both external and internalized. While community members and Rabbinical authorities approve (filtered) mobile phone use on an individual basis, its moral and faith-related pitfalls are repeated.

In this study, we aimed to reach the most open and accessible WhatsApp groups, that may in essence form a public sphere for the Haredi society. Accordingly, the vetting process embraced a grounded system of join links. Join links are hypertext nodes that subscribe users to other groups, rather than content. Within the confinements of the enclosed Haredi society, join links are commonly spread within the groups themselves, and we have been able to follow them through systematic observation of these mobile tracts, as well as through the support of informants that have shared their past join links and facilitated our entry to these groups.

Interview transcripts and screenshot data were imported into an Atlas.ti mixed-method software. The analysis followed Marshall and Rossman's four stages (2006) with special attention to the Ethnography of Communication's methodological principles: Data organization of discourse speech events and interviews; generating categories, themes, and patterns, focusing on ways of speaking and rules of speaking while remaining open to other emergent themes; testing emergent hypotheses; and finally searching for alternative explanations. For the sake of reliability, two independent researchers scrutinized the data. Thereafter, we compared and discussed the two sets of categories that were obtained from each analysis (Marshall and Rossman 2006). The differences of interpretations of the findings between our independent researchers were settled through dialogue, thereby attaining a high inter-rater reliability level (Olesen et al. 1994).

\section{Results}

From the 48 WhatsApp groups followed, seven categories were identified to encompass the corpus of these data: (1) News (termed Nayess in Haredi lingo); (2) religion (i.e., sermons, Q\&A and inspirational anecdotes); (3) Hasidic music and videoclips; (4) voluntary and communal aid (termed gmilut hasadim); (5) regional groups (i.e., Haredi areas and some of mixed towns or neighborhoods); (6) political groups; (7) instrumental groups (for example jobs, sales and profession-specific)

It should be noted that, occasionally, the discourse within groups that profess a designated type may go adrift, yet is usually directed back promptly by either administrators or lay community members. Thus, an overall consistency was found in the discussed content, which may differ from other WhatsApp groups that may be steered by altering interests or spontaneous/contingent connotations.

An analysis of the WhatsApp postings, alongside the conducted interviews identified two facets that characterize mediatization of Haredi communality via SNS platforms: (a) reconstructing the Holy community online; (b) renegotiating the enclave.

\subsection{Reconstructing the Holy Community Online}

In their WhatsApp activities, users express an aspiration to display their overt affinity towards the community and their offline enclave identity. This communal steadfastness is manifest through symbolic means and choice of discursive themes. Accordingly, themes are selected to reflect issues that 
are among the communities' primary concerns. Also, rules of conduct that characterize the community are highlighted. This aspiration has been identified in three key themes that reflect perceived strengths, lending to a narrative of self-empowerment: (i) Symbolically appropriating social tracts; (ii) strength in numbers; (iii) callings community members to act Haredi.

\subsubsection{Symbolically Appropriating Social Tracts}

The findings identify a myriad, yet clear, use of symbols that serves as an emblem to publically discern the community's identity, signifying communal distinction and boundaries. Accordingly, a recurring use of iconic Haredi images in icons and banners was found. Group icons often portray a generic visualization of Haredi folk, emphasizing their distinct dress features and beards. Other common icons offer portraits of well-known Haredi sages (see Figure 1). It should be noted that amongst the portraits of the sages, those of Chabad, Breslov and devout Sephardi spiritual leaders were by far the most prominent. Only Nayess groups dedicated to Haredi affairs displayed portraits of other denominational leaders in their banner (it should also be added that various Haredi rabbis religiously prohibit taking and using their pictures).

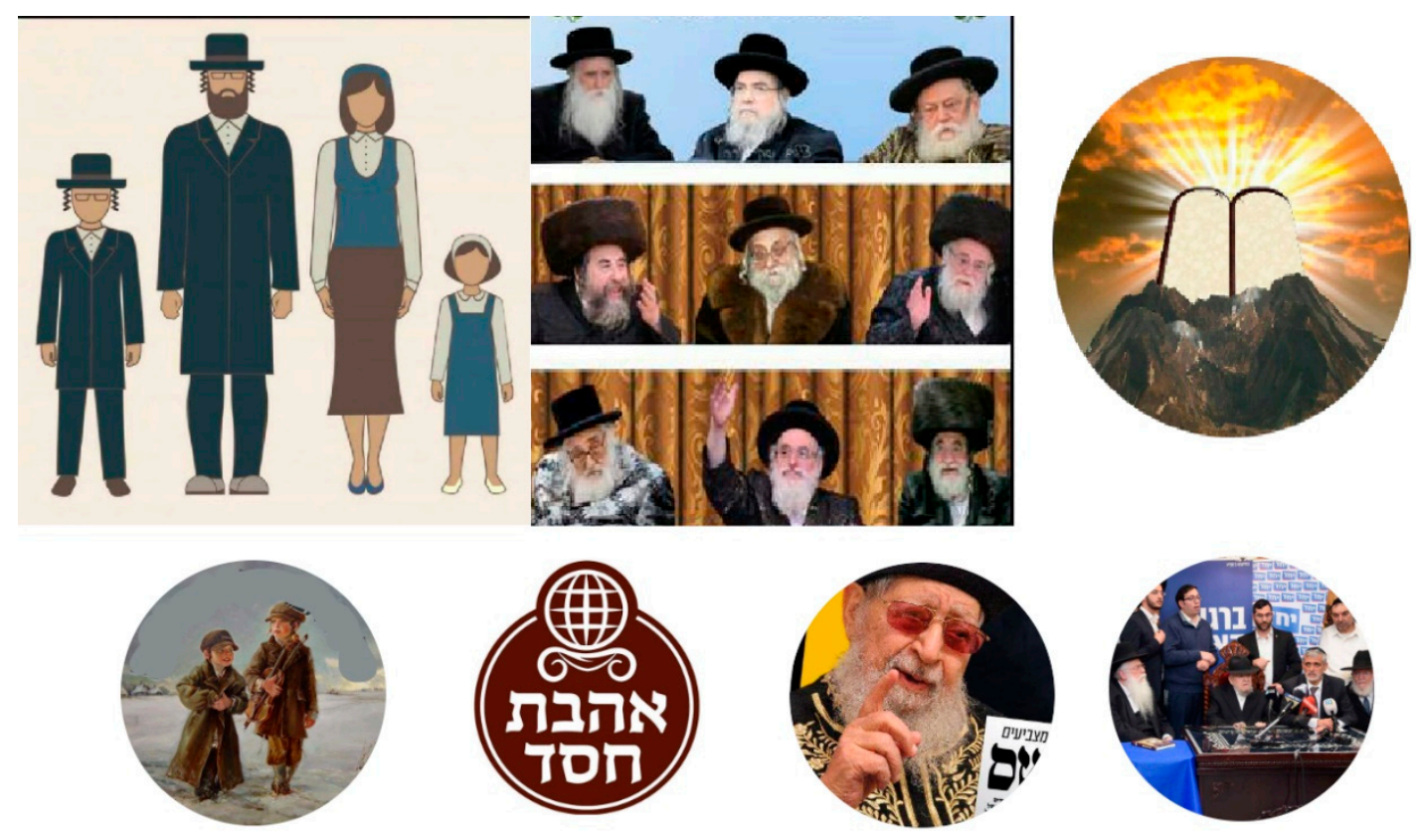

Figure 1. WhatsApp Groups' Icons.

An apparent difference is found in users' profile pictures. As each user can select an icon to represent their WhatsApp persona, subscribers diversify in their image selection. The choices vary between employing iconic images of the community (e.g., rabbis, Haredi clipart illustrations), nature shots, their personal portrait photos, or refraining from uploading any image. Chabad, Breslov and devout Sephardic rabbis' portraits were the most popular for profile pictures as well as for group banners.

Another strategy to indicate the group's compatibility to Haredi standards is to demand compliance to rules originating from Haredi social regulations (as described in the literature review). Group descriptions often include statements such as "only modest content is allowed" (retrieved July 2018), or "this group is for men/women only" (retrieved May 2018), displaying conformity to Haredi sex segregation norms, or "links to groups 24/6" (retrieved July 2018), conforming to Sabbath laws. It should be noted that most of the groups followed were not gender segregated, yet most content uploaders and administrators were male.

Communal key practices are highlighted through a cyclical iconographic portrayal. Every Friday eve, minutes before the Sabbath, group administrators announce that the group is closed, thus adhering 
to the prohibition of electricity and internet use. This announcement is accompanied by citing a biblical excerpt. Originally, administrators relied on the good will of subscribers to respect this requests, however, since WhatsApp added a feature which prevents non-administrators from posting, administrators are able to guarantee that no user will transgress the dictum (see Figure 2). As the Sabbath ends, the administrators turn this feature off, and they usually add a greeting for the upcoming week. Thus, through these opening and closing images, administrators highlight the groups' adherence to religious mores, emphasize their own participation in advancing the holy community's practices and create a recurring ritual to frame the beginning and ending of the Sabbath.

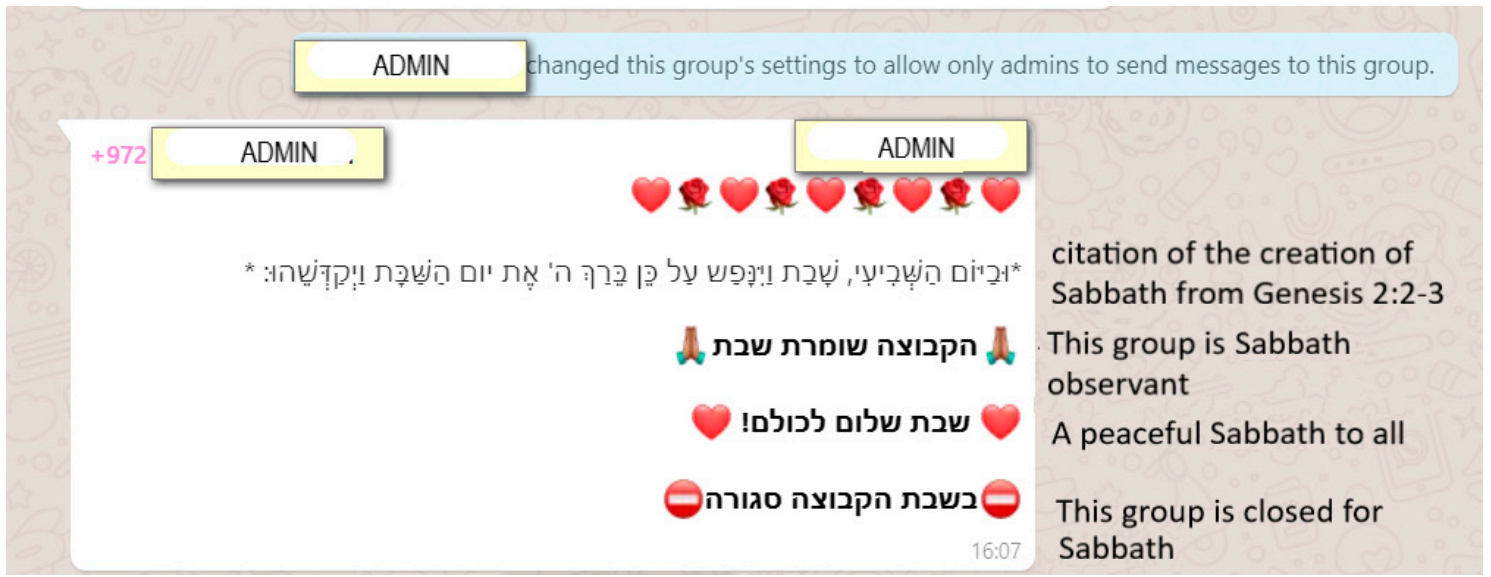

Figure 2. Group administrator turns on admin posts only feature and announces the group closed for Sabbath. Instrumental group, October 2018.

One SNS feature which seems to have permeated all groups and user types is the use of emoticons. They were utilized either as ornaments bearing no meaning, such as the top line of hearts and flowers in Figure 2, or as means to accentuate written messages as demonstrated by the emoticons used in Figure 2(middle), Figures 3 and 4. However, maybe in consideration of the less adept users, no examples in which emoticons completely replace written words were found. While emoticons are considered legitimate, the playful typographies and orthographies social networks are famous for (Danet 2001; Vaisman 2014) were not found on any group (e.g., pl@y for play, u for you). The only legitimate insider's lingo is the religious one, including many acronyms and code words.

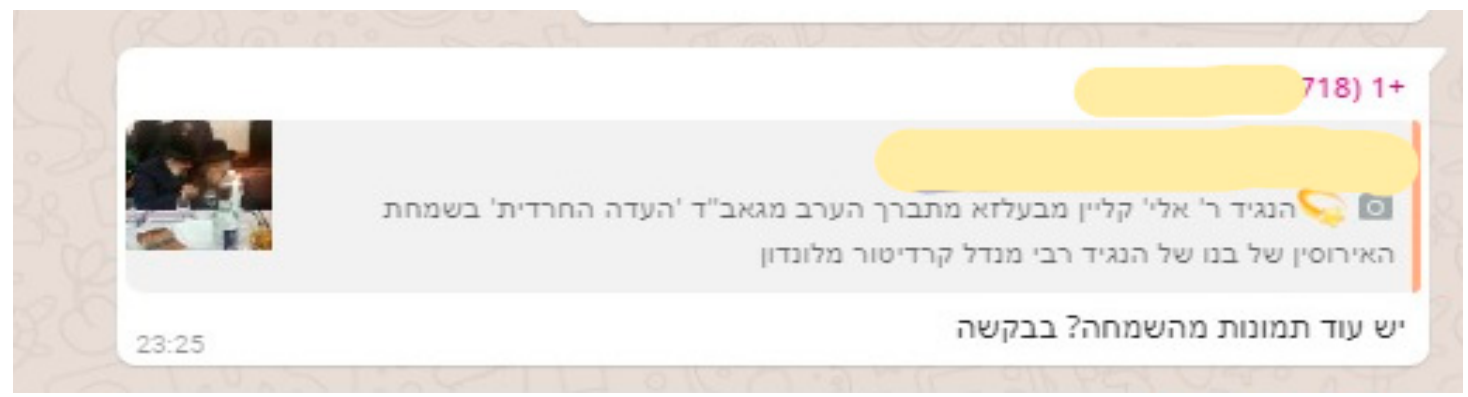

Figure 3. A non-active user pleads an administrator for more pictures from an event. February 2018. 


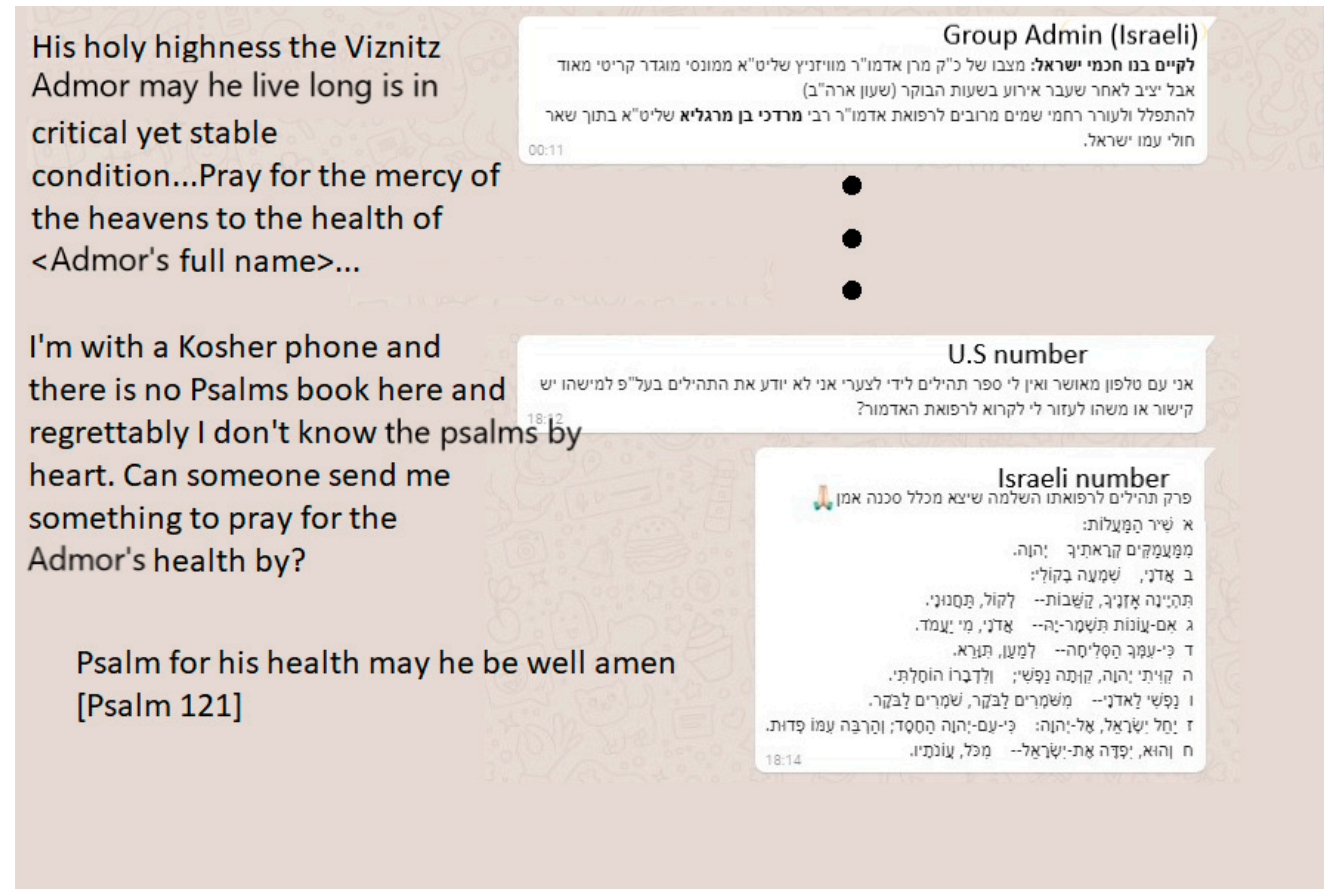

Figure 4. Parts of discussion concerning Viznitz Monsey's hospitalization. Nayess group, March 2018.

Subscribers affiliated with Chabad, Breslov and the devout Sephardi generally show more proficiency in SNS and instant messaging styles and etiquette than Haredi users from other denominations. They freely incorporate graphics (Jpegs, GIFS and stickers), write short messages, and insert links to other platforms when they wish to transfer longer content. Figure 5 shows how in a religious oriented group, one user posts a plain text message long enough to require user action to display its entirety, while the next user, a woman affiliated with Chabad, posts an elegant sticker reminding readers of a charity decree without explaining it. Only insiders or informed outsiders will understand the sticker.

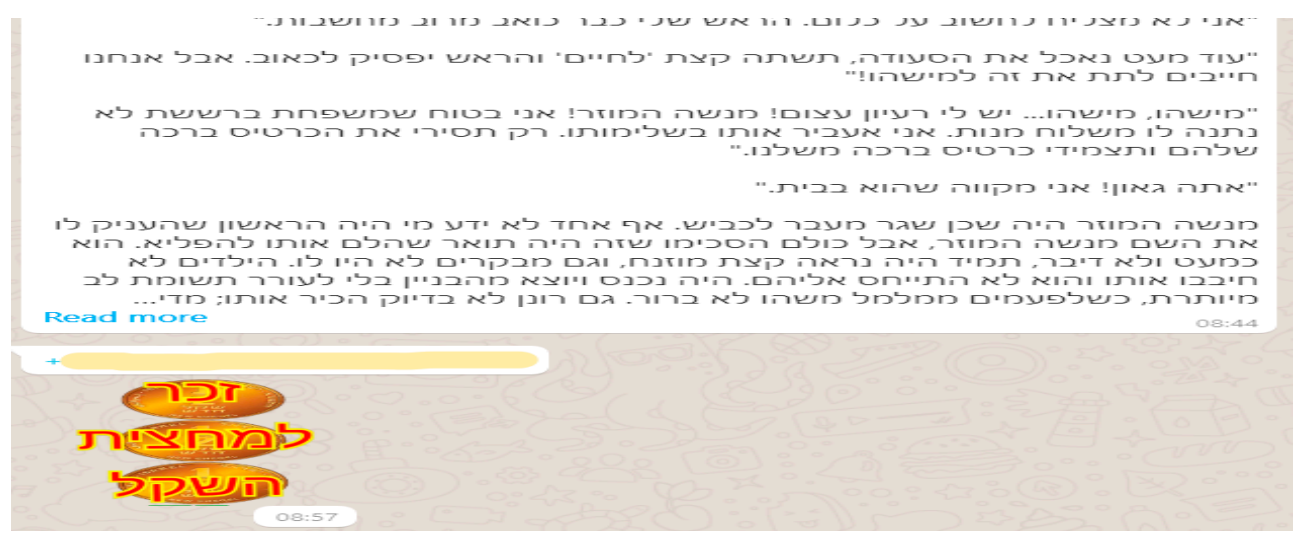

Figure 5. Haredi subscribers display different SNS/MIM proficiencies. religion group, March 2019.

It should be noted that non-Haredi groups' administrators occasionally invite Haredi users to join their WhatsApp groups. These groups facilitate Haredi subscription by conforming to much of the symbolic emblems that ornate Haredi tracts, thus emphasizing it as a safe space for Haredi participation (compare with Golan and Campbell 2015).

Comparing our findings with semiotic analysis of offline markers in Haredi neighborhoods and mass-media (Katz 2010; Heilman 2006; Shandler 2009), it was found that offline symbols were eagerly brought online, but when certain platform features and norms were not depicted by users as 
contrasting Haredi tracts, they were applied as well. Therefore, Haredi WhatsApp groups displayed a unique mix of SNS and Haredi symbolism and etiquette. Group administrators and content uploaders creatively use platform features to reestablish religious and social offline standards, but also show some acceptance of media logic. The next two sections discuss how traditional norms of speech, and popular subjects, are mirrored and transformed in SNS discourse.

\subsubsection{Strength in Numbers}

A key issue in every Haredi denomination is displaying its clout versus other Haredi sub-groups and the non-Haredi branches. To elevate their status, members often stress their denomination's vitality and ability to mobilize significant crowds (Heilman 2017, p. 261). Online, this issue is often promoted via the use of galleries. A gallery is a collection of images, and in some platforms, also short videos, documenting communal events. Galleries have originated, and are still popular, in Haredi printed press (see Baumel 2006, p. 69). However, as photographers utilize online affordances to publish more pictures and add videos, they also flourish online. Most galleries present pictures of huge Haredi crowds, usually surrounding at least one court ${ }^{1}$ leader, including glorifying descriptions (see Figure 6):

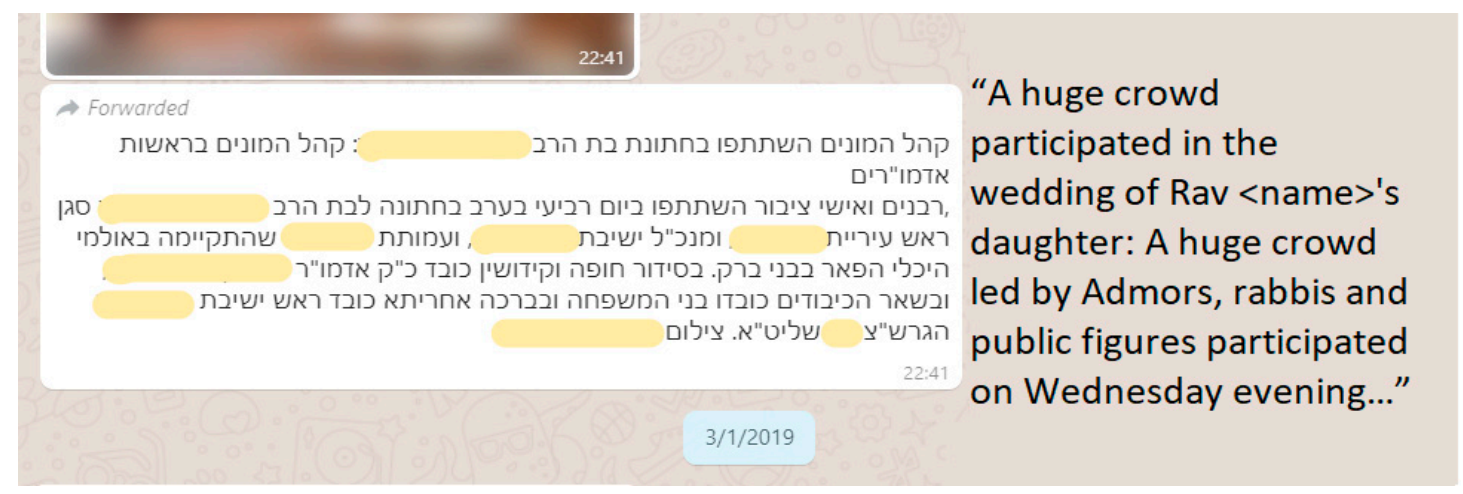

Figure 6. A typical gallery label. 'Nayess' group, February 2019.

As a group administrator explained, small courts and Yeshivas pay photographers to document and publish their gatherings. Photographers are duly expected to upload these images and videos in select groups, so as to gain exposure (Interview, December 2018). In the Nayess groups, members often ask for more pictures from their court's events to be uploaded, and sometimes complain when they feel their denomination failed to receive adequate publicity (see Figure 3).

Unlike more traditional Haredi media (e.g., printed press), Nayess, local, and political Haredi WhatsApp groups allow for some level of criticism or at least doubts. In the following example (see Figure 7), a post is seen boasting an unprecedented attendance in a denominational court event, in line with the aforementioned practice. However, this post is followed by a diminution of the statement. This belittling, although subtle, implicitly sheds doubt over the significance of the celebrated denomination and clout of its leadership. This criticism did not lead to a ban, or even to a warning, of the user. This demonstrates a relatively tolerant atmosphere online.

1 Within the Haredi society, Hassidim is a major branch, which is divided into dynastic groups known as "courts". Each court is headed by its own rabbi, has its own institutions and follows its specific set of customs (Golan 2013). 


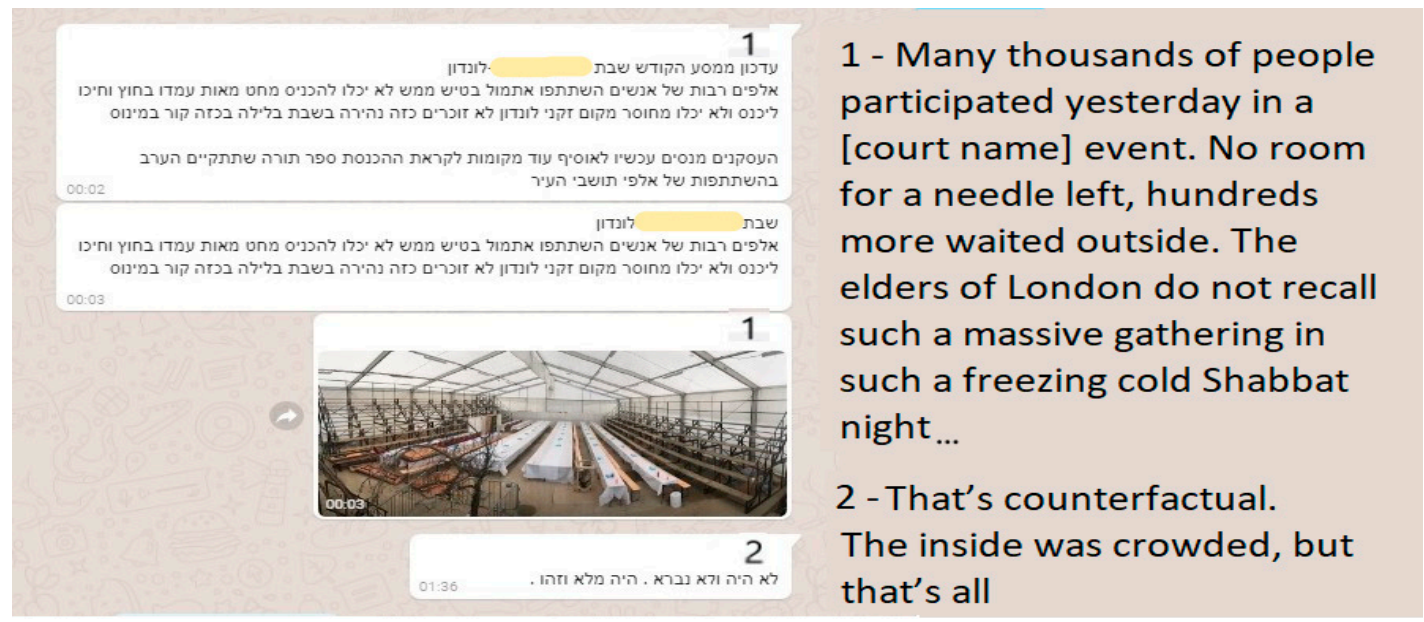

Figure 7. Posted on a Haredi Nayess WhatsApp community, February 2018.

Through the mediatized work, members have indeed replicated the offline practice of participation augmentation. However, in spite of media affordances enabling administrators to sanction disparaging participants, slight deviations and critical points are tolerated within (and perhaps due to) this medium, thus offering a track for users to voice their opinions.

\subsubsection{Calling Community Members to 'Act Haredi'}

Ethnographers of Haredi (offline) communities often depict how their members are continuously driven to act Haredi (Tavory 2016; Zicherman 2014). The conceptual framework of summoning, developed by Tavory (2016), details this conduct as a Haredi identity constantly called into being. Different types of social interactions are used, regulated or spontaneous, originating from within or from outside the community. On the studied WhatsApp groups, it was found that the most prevalent summoning methods were those stemming from within the community. Specifically, praying for unfortunate community members and asking for donations.

Tavory views (offline) calls for prayers concerning ailing or misfortunate Haredis as a means to "insert congregants— the vast majority of whom didn't know the [person] ... into a communal affair ... [as] active protagonists in the affair" (Tavory 2016, p. 62). Online, however, this practice can be divided according to the prayer's objective. Thus, prayers for the well-being of spiritual leaders echo, even amplify, the offline function depicted by Tavory. Users can publicly perform their membership throughout the Haredi world. This, in turn, offers a previously unattainable multi-national solidarity that alludes to a pan-Haredi identity, which breaches the local boundaries described by Tavory (see Figure 4).

However, on the researched WhatsApp chat groups, calls for designated prayers often play out differently, particularly contingent to the object of prayers (i.e., directed to the well-being of lay community members versus that of rabbinical leaders). Online requests to pray for lay community members mostly serve as ritual openings for sermons, which are delivered on the group feed without encouraging ongoing involvement in a communal affair (e.g., visiting or inquiring about their wellbeing). Typically, members are asked to pray for a named sick person, the wellbeing of IDF soldiers, and the entire Jewish people, before reading a following sermon or inspirational story. Apparently, to this initial posting, group members understand that no response is required.

It can be seen that through the mediatization of summoning, users have formed a discursive format for delivering religious content and achieving communal solidarity. However, through this mediatized format, an emphasis is placed on the social status of the object of prayer. Thus, prominent figures gain recurrent attention, while lay members are spotlighted on a one-time basis. 
To conclude, while the very use of SNS is seen as deviating from the enclave's moral code, administrators invest immense efforts to mark their groups as pious spaces that uphold communal boundaries. To do so, they constantly insert references and reminders to group members. Thus, they highlight that the involved users are still on Haredi turf and committed to Haredi values and mores. This, however, does not prevent skilled users from incorporating SNS and instant messaging to the chat, as the frequent use of emoticons and of the most update platform's features show.

\subsection{Renegotiating the Enclave}

While the previous section showed how both administrators and subscribers try to mimic offline Haredi communality in WhatsApp groups, the findings demonstrate that administrators decrease their vetting stringency. Moreover, the themes discussed on the group's walls show an expansion of legitimate moral scope in comparison with other public Haredi media. By doing so, they de facto promote a sense of pan-Haredism and inter-Jewish connections. Hence, through the diffuse properties of SNS, the enclave's boundaries are reshaped. Three manifestations attesting to the nature of online communal boundaries will be elaborated upon: Language choice, denominational inclusiveness and inclusiveness through political discourse.

\subsubsection{Language Choice}

Code switching, i.e., speakers alternating between languages in the context of a single conversation, is well documented in sociolinguistic scholarship, including that of internet research (Danet and Herring 2007). The sociolinguistic legacy of Haredi communities has highlighted the ways in which language choice serves as a telling indicator of the strength of insular communities' boundaries (Assouline and Dori-Hacohen 2017; Baumel 2006; Heilman 2006). Assouline and Dori-Hacohen (2017) show how journalists speak in Yiddish to mark the interviewee as an insider and switch to English when he displays otherwise. Heilman, in his study that focuses on street posters affixed in US Orthodox neighborhoods, asserts that "the use of English, Hebrew or Yiddish says something about the sociocultural orientation and ideology, especially an ability, willingness, or refusal to be fully part of the surrounding ... society" (Heilman 2006, p. 214).

Following this criterion, content uploaders in the examined WhatsApp groups are able, and willing, to be integrated into Israeli society, as nearly all messages were found to be in Hebrew. While Yiddish still holds high status in some Haredi subgroups, its use is mostly symbolic and is scattered to season the text. This is another symbol reminding users to respect the Haredi communal identity. For example, religious oriented and Nayess groups display recurrent use of Yiddish idioms and words such as Heimishe (Yiddish for homely), and jpegs displaying front pages from Haredi-Yiddish print press are occasionally uploaded there. Members of music and videos group frequently upload Yiddish music and album covers yet describe their uploads in Hebrew.

In the study's research corpus, aside from Hebrew and Yiddish, other languages were seldom observed. The exceptions included English and French Chabad advertisements, and an English document uploaded to a Nayess group, quickly followed by a request by one of the administrators not to upload English materials again. The choice of Hebrew facilitates inclusion of non-Haredi membership, and the membership of many Israeli Haredi courts, in which youngsters hardly use Yiddish nowadays (see Baumel 2006).

\subsubsection{Denominational Inclusiveness}

Public Haredi WhatsApp groups were found to openly promote mutual respect and solidarity between all Haredi denominations. The strategies that were identified to advance this observed objective included: highlighting inter-denominational gatherings, downplaying disputes and enforcing respectful discourse when conflicting denominational norms arise.

The aforementioned galleries are the most prevalent method of highlighting inter-denominational gatherings (e.g., weddings, religious holidays). This is to say, most galleries display events in which 
members of various Haredi communities celebrate together. While such gatherings elicit reactions on WhatsApp groups in general, galleries documenting encounters between denominational leaders were noted to garner the largest number of responses, and the most emotional as well. Rather than taking a critical, conflictual or dispassionate discussion, the participants often use enthusiastic expressions to address these happenings. Expressions such as "in a rare and spiritually exulting event", or "participants were in tears to witness the event" (uploaded on June 2018), attest to users' positive and intense reactions.

Furthermore, administrators were proactive in downplaying disputes. Thus, users engaging in disputes within or between denominations were often warned and requested to delete their comments, or they were banned. Similarly, it was found that continuous efforts for enforcing respectful discourse. Accordingly, whenever uploaded messages were deemed by group administrators as disrespectful towards named denominations or their spiritual leaders, public reprimands and bans ensued. A typical phrasing of warnings is "Any further disrespect towards <court name $>$ will result in banning" (April 2018). In contrast, criticism of specific members of a lower religious hierarchy was allowed in most groups. Pan-Haredi solidarity was also promoted by paying attention to document as many denominations as possible, and by uploading welcome messages whenever new subscribers from a less frequented denomination join the group. However, as previously noted, Chabad and Breslov, implementing their outreach policies, were dominant in these arenas as well.

\subsubsection{Inclusiveness through Political Discourse}

Exploring Haredi WhatsApp groups, we have found an ongoing engagement with non-Haredi users that obfuscates external boundaries. The most recurrent theme of such engagement involved political discussions. In these discussions, a clear and almost single-voiced discourse could be identified, of a Hawkish nature with regard to the Israeli-Arab conflict. While these groups are defined as a mobile Haredi space, they often include political voices that go beyond Haredi-communal political discourse.

For example, during the Israeli national election campaign of 2019, many of these groups posted infomercials and links propagating extreme right-wing parties lead by national Orthodox representatives (see Figure 8). These posts did not lead to any bans. In the few cases uploaders were warned or requested to delete such posts, it was for reasons of irrelevance to the group's topics and not as rejection to the message's content.

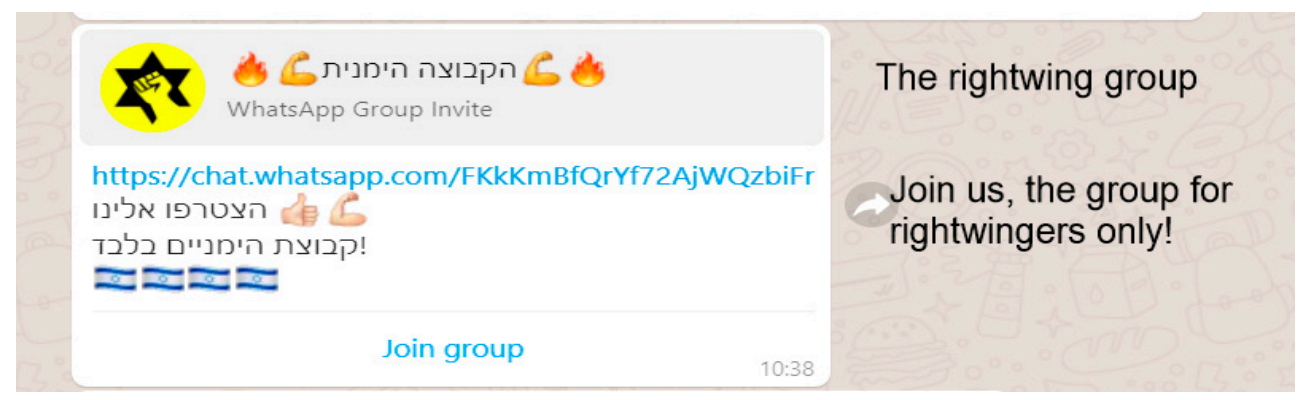

Figure 8. Link to an extremist right-wing group posted by a non-Haredi subscriber. Instrumental Haredi group, January 2019.

While catering to a predominantly Haredi public, and (as aforementioned) hosting its symbolic tracts, WhatsApp groups often populate non-Haredi members. Most salient, in this regard, are the Chardali groups that are of a modern national Orthodox background, yet approximate Haredi ideals and practices (Zoldan 2019). As the Chardali groups are often characterized by political activism with Hawkish leanings, much of the political activity may be initiated by these group members, particularly prior to an election. Indeed, the popularity of these groups invite political activists and agencies to approach these WhatsApp groups and hinge on past election sentiments that underscore Haredi inclinations towards Hawkish viewpoints (Zicherman 2014; Zoldan 2019). 
Additionally, during the same political campaign, users repeatedly posted links to other WhatsApp groups supporting Netanyahu, the incumbent (secular) right-wing prime minister, and incited against what he claims are his most bitter rivals-institutionalized news outlets and leftist politicians (see Figure 9).

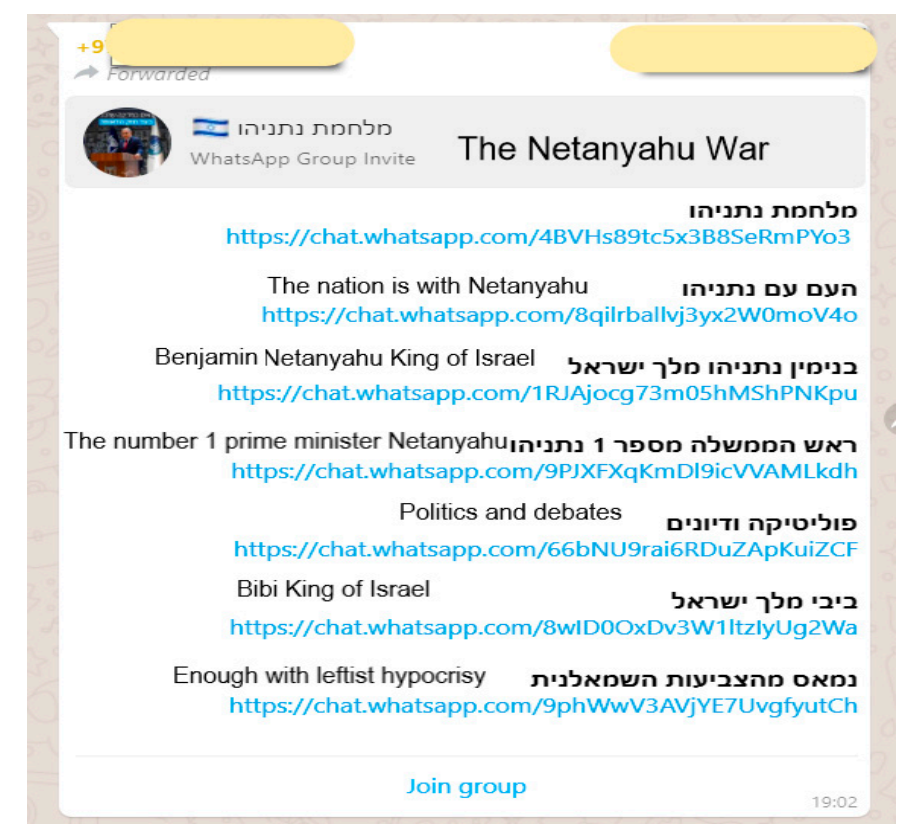

Figure 9. Links to pro-Netanyahu groups posted by a non-Haredi subscriber. Political Haredi group, 2019 election campaign.

In sum, scholars have often underscored the boundaries laid by Haredi leaders and their agents (Tavory 2016; Zicherman 2014), as well as its manifestations on communal websites (Golan and Campbell 2015). However, the findings underscore WhatsApp groups as constituting a space that connects users of different affiliations (Haredi and otherwise) through continuous discussions over political content. The content that displays homogenous political leanings may resemble a discursive echo chamber (See Pariser 2011). A space that allows Haredi groups of different denominations, as well as members of the Chardali group and beyond, to take part in a joint political discourse under the Haredis' digital canopy.

To conclude, by renegotiating the Enclave, Haredi group administrators and users negotiate the enclave's internal and external boundaries. Choosing the Hebrew language signifies their willingness to accommodate non-Haredi Israelis and young Haredis. The negotiation of internal boundaries takes the form of promoting denominational inclusiveness. This exhibits moving from the offline practice of aggrandizing one's group to a practice of showing the utmost respect for every rabbi that is considered a sage by some denominations. Taking part in, or even silently observing, the political discourse of WhatsApp groups in which non-Haredi Israelis are vocal participants signifies a weakening of external boundaries.

\section{Discussion and Conclusions}

By examining mediatization effects on religion, this study focused on the communal variant. Under this prism, the negotiation of communal identity has been examined, as it manifests in mobile communications. Past studies that focused on the mediatization of religion highlighted changes in religious exegesis, ritual and practice to accommodate a media logic (Golan and Martini 2018; 
Valibeigi 2018; Radde-Antweiler 2006; Tsuria 2016). Alternately, this study found that social network sites offer the populace of a fundamentalist group a platform for voicing and negotiating their positions as communal citizens within a public sphere that was previously denied by the Haredi press, religious authorities and such.

Indeed, the Haredi community enclave has been at the heart of studies that discuss boundary construction and maintenance among insular religious groups (Lehmann and Siebzehner 2006; Sivan 1995; Friedman 1991). However, in recent years, researchers have noted a rise in the number of members that increasingly integrate themselves into their surrounding society. While the spheres of integration may vary and include education, politics and economy (Stadler 2012; Zicherman 2014; Zoldan 2019), the mechanisms perpetuating such transitions have mostly remained in the shadows. This study suggests SNS communities to be primary vehicles for promoting and deliberating these processes.

Communal WhatsApp groups were found to share valuable information, and spread Haredi culture and values among its members of different denominations, as well as among non-Haredi sympathizers. Beforehand, we discussed Haredi believers' primary precepts that shape their offline social life (i.e., locality, gender segregation and external boundaries). Comparing these key precepts to their mobile phone collectives, some similarities could be identified. Indeed, communal WhatsApp groups were found to spread Haredi culture and values among its members of different denominations, as well as among non-Haredi sympathizers and employ symbolic means to underscore their adherence to the community. However, in terms of these three basic precepts, WhatsApp groups were found to diverge from (rather than counter, or deeply deviate) the basic social order. While keeping the discourse familiar and safe religious-wise, with Sabbath observance being the most prevalent example, these groups often traverse the main social regulations of locality, gender segregation and external boundaries previously mentioned. Moreover, these groups were found to be more inclusive than their offline counterparts. By doing so, they create a space for dialogue between previously unexpected interlocutors, both from within the Haredi sub-groups and beyond.

Arguably, the most salient effect of the mediatization of Haredi communality is the creation of a platform to voice the grassroots majority of a reclusive community, since in the past, the public sphere has been dominated by religious authorities and their proxies (Caplan 2006; Michelson 1990). By reviewing the WhatsApp groups, it gives an unobtrusive access into the informal culture of the Haredi. The findings uncovered key points of interest among Haredi users which included: Communal news, religion, hasidic music and videoclips, voluntary and communal aid, regional groups, politics and instrumental issues such as jobs and sales. Given these groups' relative release of religious authority and institutional supervision, users are free to voluntarily select their groups of affiliation. Accordingly, they enter and exit these mobile groups with little to no fear of external sanctions (compare with the code of informality, Kahane 1997). Under these emergent circumstances, Haredi WhatsApp groups have demonstrated themselves as platforms for instrumental, recreational and identity work. Instrumental, as they offer advice for the working public of the community; recreational, as they furnish an alternative to a rigid lifestyle that has historic reservations concerning leisure activities (Aharoni 2014) and identity work, well described throughout our findings (iconography, language use, praxis), to enhance a sense of belonging and solidarity. This collective sense of participation may not carry the ecstatic liturgical essence of Pentecostal ceremonies, for example, as referenced by Marty and Appleby, in their seminal discussion on fundamentalism (Marty and Appleby 1991, p. 831). However, this participation carries an informal weight, which includes voluntary participation and expressive affordances, that can foster commitment to tenets elected by users, and enhances the sense of belonging amongst members.

Furthermore, the study specified the ways in which this participation nurtures a process of identity making. This process unfolds through the two facets elaborated in our findings. Accordingly, through symbolic means, the mediascape is appropriated. Moreover, a discourse of communal empowerment is highlighted (strength in numbers), and overt appeals to follow the communal pathway (calls to act Haredi) are pronounced. Furthermore, as users playfully engage in linguistic code switching 
(language choice), the research uncovered the ways in which the religious enclave is reflected upon, reconsidered and reconstituted on these mobile communications. Moreover, while often pronounced, the inner boundaries of denominations loosen to enable inter-group dialogue, and a political tract for propagating ideological worldviews is fostered that includes non-Haredi participants.

In spite of the temporary reduction in the rigidness of communal boundaries, the question of inter-denominational power relations still comes into play. However, rather than mirroring the multilayered status relations of each sub group, this study identified a liminal space in the studied WhatsApp groups. A space dominated by the emergent class of working Haredi participants in an apparent Pan-Haredi surrounding. This class nowadays includes over $52 \%$ of adult males between 18-65 (Malach and Cahaner 2018) (not including undeclared workers). However, this seemingly open space for discourse is dominated by three main groups, namely that of Chabad, Breslov and devout Sephardic participants. Scholars have previously noted these groups' affinity towards new media and their engagement with modern society. Chabad and Breslov have been noted for their outreach activities (Bilu and Mark 2017). Devout Sephardi Haredis are known for allowing group members to retain close familial, friendly and professional connections to non-Haredi Jews (Lehmann and Siebzehner 2006; Le'on 2009). Accordingly, Chabad and Breslov participants are prominent in uploading their denominations' sermons, music, videos, and outreach media. Devout Sephardi Haredis are prominent in national and regional news groups, election campaigns' groups and commercial groups.

Members of these denominations also displayed better skills and awareness in applying platform features and etiquette. In contrast, users of other denominations were silent observers in most groups. When being active, mostly in news groups focused on internal Haredi affairs, they usually displayed less awareness of various features and platform norms of conduct. Thus, it seems further research is warranted to fully explore this finding, as questions of power and discourse over religious WhatsApp groups are strongly invoked.

Current scholars of the Haredi society point to its incremental integration into Israeli society (Zicherman 2014; Zoldan 2019). However, these studies refrain from identifying the ways in which its fundamentalist identity is maintained, reconstructed or dissipated. Examining public WhatsApp groups, we identified a clear voice that calls into play a preservation of fundamentalist identity, in line with what Almond, Sivan and Appleby, refer to as world creator fundamentalism (Almond et al. 1995, pp. 427-29). This is to say, we find a mode of activity that is directed towards preserving the communal identity through a gradual and accumulative intervention in Israeli societies' key institutions (e.g., political, judiciary, economy); outreaching to new members, while offering a selective relaxation of their boundaries, particularly between what is deemed the enemy and associate group member (most salient in the shared spaces with the national Orthodox variant). Thus, rather than identifying media tracts as another manifestation of the fundamentalist groups' reclusive nature as world renouncers, we find an active pursuit of participation, with a subtle, yet meaningful, modes of acting in the society at large and aiming to influence its character.

To conclude, the mediatization of religion was found to open the enclaved community to internal dissent and grassrooted-voiced participation. Paradoxically, these strands of democratization may lead to a mere change in its fundamentalist orientation, rather than integration with western-liberal and modern ideals.

Author Contributions: Conceptualization, N.M.-S. and O.G.; formal analysis, N.M.-S. and O.G.; investigation, N.M.-S.; writing—original draft, N.M.-S.; writing—review and editing, N.M.-S. and O.G.

Funding: This work was funded by the Ministry of Science in Israel (Grant Nr: 3-15724) and the President of the State of Israel's Scholarship for Research Excellence and Innovation, allocated by Israel's Estates Committee.

Acknowledgments: The authors would like to thank David Herbert for initiating this important volume and offering insightful suggestions. Further gratitude is expressed to the editorial staff, and to the four anonymous reviewers for their constructive feedback and helpful comments that helped sharpen the paper at hand. The authors would also like to thank Aref Badarne for his assistance in all stages of the manuscript's preparations. 
This work was supported by the Ministry of Science in Israel. Nakhi Mishol-Shauli's work is supported by the President of the State of Israel's Scholarship for Research Excellence and Innovation.

Conflicts of Interest: The authors declare no conflicts of interest. The founding sponsors had no role in the design of the study; in the collection, analyses, or interpretation of data; in the writing of the manuscript, and in the decision to publish the results.

\section{References}

Abramac, Gabi. 2015. What's Up with WhatsApp in the Haredi World? In Conflict and Transformation. Edited by Tadej Pirc. Ljubljana: A Priori, pp. 153-70.

Aharoni, Matan. 2014. Eliciting “Kosher Emotions" in Ultra-Orthodox Jewish Women's Film. In The Emotions Industry. Edited by Moshe Mira. New York: Nova Publishers, pp. 95-116.

Almond, Gabriel A., Emmanuel Sivan, and Scott R. Appleby. 1995. Explaining Fundamentalisms. In Fundamentalisms Comprehended. Edited by Martin E. Marty and Scott A. Appleby. Chicago: Chicago University of Press, pp. 425-44.

Assouline, Dalit, and Gonen Dori-Hacohen. 2017. Yiddish across borders: Interviews in the Yiddish ultra-Orthodox Jewish audio mass medium. Language \& Communication 56: 69-81.

Baumel, Simeon D. 2006. Sacred Speakers: Language and Culture among the Ultra-Orthodox in Israel. New York: Berghahn Books.

Bilu, Yoram, and Zvi Mark. 2017. "You shall spread out to the west and to the east, to the north and to the south"-Breaching Boundaries and Messianism in Chabad and Breslov Hassidic Courts. In Stop—No Borders In Front of You! About Borders and the Lack of Them in Israel 2017. Edited by Zubida Hani and Raanan Lipshitz. Rishon LeZion: Miskal-Yedioth Ahronoth Books and Chemed Books, pp. 575-90.

Boczkowski, Pablo J., Eugenia Mitchelstein, and Mora Matassi. 2018. 'News Comes across When I'm in a Moment of Leisure': Understanding the Practices of Incidental News Consumption on Social Media. New Media $\mathcal{E}$ Society 20: 3523-39. [CrossRef]

boyd, danah. 2010. Social network sites as networked publics: Affordances, dynamics, and implications. In $A$ Networked Self. Edited by Zizi Papacharissi. London: Routledge, pp. 47-66.

Brown, Benjamin. 2017. The Haredim: A Guide to Beliefs and Sectors. Tel-Aviv: Am Oved. (In Hebrew)

Campbell, Heidi A. 2010. When Religion Meets New Media. London: Routledge.

Campbell, Heidi A., and Mia Lövheim. 2011. INTRODUCTION. Information, Communication \& Society 14: $1083-96$. [CrossRef]

Caplan, Kimi. 2006. Profiles in the Haredi press in Israel: History, development, and characteristics. Segmental Media in Israel 3: 1-47.

Church, Karen, and Rodrigo De Oliveira. 2013. What's Up with WhatsApp?: Comparing Mobile Instant Messaging Behaviors with Traditional SMS. In Proceedings of the 15th International Conference on Human-Computer Interaction with Mobile Devices and Services. New York: ACM, pp. 352-61.

Cohen, Yoel. 2017. The media challenge to Haredi rabbinic authority in Israel. ESSACHESS-Journal for Communication Studies 10: 113-28.

Danet, Brenda. 2001. Cyberplay: Community Online. Oxford: Berg.

Danet, Brenda, and Susan C. Herring. 2007. The Multilingual Internet: Language, Culture, and Communication Online. Oxford: Oxford University Press on Demand.

Ekstrand, Victoria S. 2003. Unmasking Jane and John Doe: Online Anonymity and the First Amendment. Communication Law and Policy 8: 405-27. [CrossRef]

Fader, Ayala. 2017. The counterpublic of the J(ewish) Blogosphere: Gendered language and the mediation of religious doubt among ultra-Orthodox Jews in New York. Journal of the Royal Anthropological Institute 23: 727-47. [CrossRef]

Finkelman, Yoel. 2014. The Ambivalent Haredi Jew. Israel Studies 19: 264-93. [CrossRef]

Francesc-Xavier, Marin. 2015. Islam and Virtual Reality. How Muslims in Spain Live in the Cyberspace. In Negotiating Religious Visibility in Digital Media. Edited by Miriam Diez Bosch, Josep Lluis Mico and Josep Maria Carbonell. Barcelona: Blanquerna Universitat Ramon Llull, pp. 81-89. 
Friedman, Menachem. 1991. The Haredi (Ultra-Orthodox) Society-Sources, Trends and Processes; Jerusalem: The Jerusalem Institute for Israel Studies. Available online: http://www.jerusaleminstitute.org.il/.upload/ haredcom.pdf (accessed on 10 October 2017). (In Hebrew with English Summary).

Golan, Oren. 2013. Charting frontiers of online religious communities. In Digital Religion: Understanding Religious Practice in New Media Worlds. Edited by Heidi A. Campbell. New York: Routledge, pp. 155-63.

Golan, Oren, and Heidi A. Campbell. 2015. Strategic management of religious websites: The case of Israel's orthodox communities. Journal of Computer-Mediated Communication 20: 467-86. [CrossRef]

Golan, Oren, and Michele Martini. 2018. Digital pilgrimage: Exploring Catholic monastic webcasts. The Communication Review 21: 24-45. [CrossRef]

Golan, Oren, and Michele Martini. 2019. The Making of contemporary papacy: Manufactured charisma and Instagram. Information, Communication \& Society, 1-18. [CrossRef]

Golan, Oren, and Nakhi Mishol-Shauli. 2018. Fundamentalist Web Journalism: Walking a Fine Line between Religious Ultra Orthodoxy and the New Media Ethos. European Journal of Communication 33: 304-20. [CrossRef]

Gregg, Heather Selma. 2016. Three theories of religious activism and violence: Social movements, fundamentalists, and apocalyptic warriors. Terrorism and Political Violence 28: 338-60. [CrossRef]

Heilman, Samuel C. 1992. Defenders of the Faith: Inside Ultra-Orthodox Jewry. Berkeley: University of California Press.

Heilman, Samuel C. 2006. Sliding to the Right: The Contest for the Future of American Jewish Orthodoxy. Berkeley: University of California Press.

Heilman, Samuel C. 2017. Who Will Lead Us?: The Story of Five Hasidic Dynasties in America. Berkeley: University of California Press.

Heilman, Samuel C., and Menachem Friedman. 1991. Religious fundamentalism and religious Jews: The case of the Haredim. In Fundamentalism Observed. Edited by Marty E. Martin and Scott R. Appleby. Chicago: Chicago University Press, pp. 197-264.

Hjarvard, Stig. 2012. Three forms of mediatized religion. Changing the public face of religion. In Mediatization and Religion. Edited by Stig Hjarvard and Mia Lövheim. Gothenburg: Nordicom, pp. 21-44.

Hoffman, Adam, and Yoram Schweitzer. 2015. Cyber Jihad in the Service of the Islamic State (ISIS). Tel-Aviv: The Institute for National Security Studies, Tel-Aviv University.

Hoover, Stewart, and Nabil Echchaibi. 2014. Media Theory and the 'Third Spaces of Digital Religion'. Finding Religion in the Media: Work in Progress on the Third Spaces of Digital Religion. Available online: https://www.researchgate.net/profile/Stewart_Hoover/publication/287644204_The_Third_Spaces_ of_Digital_Religion/links/567825d108aebcdda0ebcb9f/The-Third-Spaces-of-Digital-Religion (accessed on 4 October 2018).

Hutchings, Tim. 2011. Contemporary religious community and the online church. Information, Communication $\mathcal{E}$ Society 14: 1118-35.

Hymes, Dell. 1989. Ways of Speaking. In Explorations in the Ethnography of Speaking, 2nd ed. Edited by Bauman Richard and Joel Sherzer. Cambridge: Cambridge University Press, pp. 433-52.

Kahane, Reuven. 1997. The Origins of Postmodern Youth: Informal Youth Movements in a Comparative Perspective. Berlin: Walter de Gruyter.

Katriel, Tamar. 2004. Dialogic Moments: From Soul Talks to Talk Radio in Israeli Culture. Detroit: Wayne State University Press.

Katz, Maya Balakirsky. 2010. The Visual Culture of Chabad. Cambridge: Cambridge University Press.

Katz, Yaron. 2012. Technology Use in the Religious Communities in Israel: Combining Traditional Society and Advanced Communications. Journal of Religion, Media \& Digital Culture 1: 1-30.

Le'on, Nesim. 2009. Soft Haredism. Religious Renewal in Sephardic Judaism. Jerusalem: Yad Ben Zvi. (In Hebrew)

Lehmann, David, and Batia Siebzehner. 2006. Remaking Israeli Judaism: The Challenge of Shas. London: Hurst.

Lev-On, Azi, and Rivka Neriya-Ben Shahar. 2011. A forum of their own: Views about the Internet among ultra-Orthodox Jewish women who browse designated closed fora. First Monday 16. [CrossRef]

Livio, Oren, and Keren Tenenboim-Weinblatt. 2007. Discursive legitimation of a controversial technology: Ultra-Orthodox Jewish women in Israel and the Internet. Communication Review 10: 29-56. [CrossRef]

Lövheim, Mia. 2017. Media and religion. In Foundations and Futures in the Sociology of Religion. Edited by Luke Doggett and Alp Arat. London: Routledge, chp. 3. 
Lynch, Gordon. 2012. The Sacred in the Modern World: A Cultural Sociological Approach. Oxford: Oxford University Press.

Malach, Gilad, and Lee Cahaner. 2018. Statistical Report on Ultra-Orthodox Society in Israel. Jerusalem: The Israeli Democracy Institute.

Marshall, Catherine, and Gretchen B. Rossman. 2006. Designing Qualitative Research. Thousand Oaks: Sage Publications.

Marty, Martin E., and Scott R. Appleby. 1991. Conclusion: An Interim Report on a Hypothetical Family. In Fundamentalism Observed. Edited by Marty E. Martin and Scott R. Appleby. Chicago: Chicago University Press, pp. 814-42.

Michelson, Menachem. 1990. Ultra-orthodox journalism in Israel. Kesher 8: 10-22. (In Hebrew).

Mishol-Shauli, Nakhi, Malka Shacham, and Oren Golan. 2019. ICTs in Religious Communities: Communal and Domestic Integration of New Media among Jewish Ultra-Orthodoxy in Israel. In Learning in $a$ Networked Society: Spontaneous and Designed Technology Enhanced Learning Communities. Edited by Yael Kali, Ayelet Baram-Tsabary and Amit Schejter. Berlin: Springer, pp. 221-41.

Neusner, Jacob. 1986. Varieties of Judaism in the formative Age. In Jewish Spirituality. Edited by Arthur Green. New York: Crossroad Publishing, pp. 171-97.

Olesen, Virginia, Nellie Droes, Diane Hatton, Nan Chico, and Leonard Schatzman. 1994. Analyzing together: Recollections of a team approach. In Analyzing Qualitative Data. Edited by Dans A. Bryman and Richard G. Burgess. London: Routledge, pp. 111-28.

Pariser, Eli. 2011. The Filter Bubble: What the Internet Is Hiding from You. London: Penguin Books.

Radde-Antweiler, Kerstin. 2006. Rituals online: Transferring and designing rituals. Online-Heidelberg Journal of Religions on the Internet 2. [CrossRef]

Rainie, Lee, and Barry Wellman. 2012. Networked: The New Social Operating System. Cambridge: MIT University Press.

Rashi, Tsuriel. 2013. The Kosher Cell Phone in Ultra-Orthodox Society. In Digital Religion: Understanding Religious Practice in New Media Worlds. Edited by Heidi Campbell. London: Routledge, pp. 173-81.

Rinallo, Diego, Pauline Maclaran, and Lorna Stevens. 2016. A mixed blessing: Market-mediated religious authority in Neopaganism. Journal of Macromarketing 36: 425-42. [CrossRef]

Rosenthal, Michele, and Rivka Ribak. 2015. On Pomegranates and Etrogs: Internet Filters as Practices of Media Ambivalence among National Religious Jews in Israel. In Digital Judaism: Jewish Negotiations with Digital Media and Culture. Edited by Heidi Campbell. London: Routledge, pp. 145-60.

Shandler, Jeffrey. 2009. Jews, God, and Videotape: Religion and Media in America. New York: New York University Press.

Shirky, Clay. 2008. Here Comes Everybody: The Power of Organizing without Organizations. New York: Penguin.

Sivan, Emmanuel. 1995. The enclave culture. In Fundamentalisms Comprehended. Edited by Martin E. Marty and Scott R. Appleby. Chicago: Chicago University Press, pp. 11-68.

Stadler, Nurit. 2009. Yeshiva Fundamentalism: Piety, Gender and Resistance in the Ultra-Orthodox World. New York: New York University Press.

Stadler, Nurit. 2012. A Well-Worn Tallis for a New Ceremony: Trends in Israeli Haredi Culture. Boston: Academic Studies.

Tavory, Iddo. 2016. Summoned: Identification and Religious Life in a Jewish Neighborhood. Chicago: University of Chicago Press.

Toor, Amar. 2015. Ultra-Orthodox Jews Are Using WhatsApp to Defy Their Rabbis' Internet Ban; The Verge. Available online: https://www.theverge.com/2015/10/27/9620752/whatsapp-hasidic-jewish-internet-ban (accessed on 17 October 2017).

Tsuria, Ruth. 2016. Jewish Q\&A online and the regulation of sexuality: Using Foucault to read technology. Social Media+Society 2. [CrossRef]

Turner, Bryan S. 2007. Religious Authority and the New Media. Theory, Culture E Society 24: 117-34.

Umble, Dianne Zimmerman. 1992. The Amish and the Telephone: Resistance and reconstruction. In Consuming Technologies: Media and Information in Domestic Spaces. Edited by Roger Silverstone and Eric Hirsch. London: Routledge, pp. 171-81.

Vaidhyanathan, Siva. 2018. Antisocial Media: How Facebook Disconnects Us and Undermines Democracy. Oxford: Oxford University Press. 
Vaisman, Carmel L. 2014. Beautiful script, cute spelling and glamorous words: Doing girlhood through language playfulness on Israeli blogs. Language E Communication 34: 69-80.

Valibeigi, Narges. 2018. Being Religious through Social Networks. In Mediatized Religion in Asia: Studies on Digital Media and Religion. Edited by Kerstin Radde Antweiler and Xenia Zeiler. London: Routledge, chp. 9.

Zaleski, Jeff P. 2002. The Soul of Cyberspace. New York: HarperCollins Publishers.

Zelenkauskaite, Asta, and Amy L. Gonzales. 2017. Non-standard typography use over time: Signs of a lack of literacy or symbolic capital? The Journal of Community Informatics 13: 72-91.

Zicherman, Haim. 2014. Black Blue-White-A Journey into Haredi Society in Israel. Tel Aviv: Yedioth Ahronoth Press and Chemed Books. (In Hebrew)

Zoldan, David. 2019. The New Ultra-Orthodox. Modiin: Kineret, Zmora, Dvir publishing. (In Hebrew)

C 2019 by the authors. Licensee MDPI, Basel, Switzerland. This article is an open access article distributed under the terms and conditions of the Creative Commons Attribution (CC BY) license (http://creativecommons.org/licenses/by/4.0/). 